\title{
Transforming Education through a Global e-Learning Model for Pediatric Diabetes and Endocrinology
}

\author{
Sze May Nga, ${ }^{a}$ Carine de Beaufort ${ }^{c, d}$ Annemieke M. Boot ${ }^{e}$ Dorothy Becker ${ }^{f}$ \\ Joseph I. Wolfsdorfg, $h$ \\ aDepartment of Paediatric, Southport and Ormskirk NHS Trust, Southport, UK; 'bepartment of Women's and \\ Children's Health, University of Liverpool, Liverpool, UK; 'Department of Pediatric Endocrinology and Diabetes, \\ Pediatric Clinic/Centre Hospitalier de Luxembourg, Luxembourg, Luxembourg; 'Department of Pediatrics, UZ- \\ VUB, Free University Brussels, Brussels, Belgium; 'Department of Pediatrics, University Medical Center Groningen, \\ University of Groningen, Groningen, The Netherlands; 'Division of Endocrinology and Diabetes, UPMC Children's \\ Hospital of Pittsburgh, Pittsburgh, PA, USA; 9Division of Endocrinology, Department of Pediatrics, Boston Children's \\ Hospital, Boston, MA, USA; 'hHarvard Medical School, Boston, MA, USA
}

\section{Introduction}

Electronic learning (e-learning) delivers education and learning through digital resources. During this COVID-19 pandemic, e-learning is extensively used and has become an increasingly important mode of delivering health-care education programs globally. E-learning is reported to be as effective as other educational approaches for the acquisition of knowledge, skills, and behaviors $[1,2]$. E-learning also has the potential to connect and engage individuals across geographic boundaries [3]. While the effectiveness of e-learning platforms may vary widely across different courses, the advantages gained from e-learning modules include flexibility of time and place, personal control over learning activities, data collection for assessments, and adaptive instructions for the learners $[3,4]$.

E-learning is now able to overcome barriers to training due to social distancing rules and provides education and learning opportunities for students, trainees, and doctors to maintain essential competences and professional development. It is particularly useful for those working on residential shifts who are subject to work hour restrictions, which often interfere with in-person attendance at didactic lectures [5] and for those who live in a remote area. E-learning may also be an opportunity to expand or tailor educational activities for learners with different learning needs. Studies have reported that elearning is not superior to conventional methods in delivering knowledge to learners. However, in addition to being an effective adjunct to conventional teaching, due to the ease of access online, advantages of e-learning include the ability to quickly revise and update educational materials (compared to textbooks that are frequently out of date by the time they are published), and the ability to serve a large number of students at a relatively low cost [6]. karger@karger.com www.karger.com/hrp (c) 2021 S. Karger AG, Base

Karger!
Correspondence to:

Sze May Ng, may.ng@nhs.net 


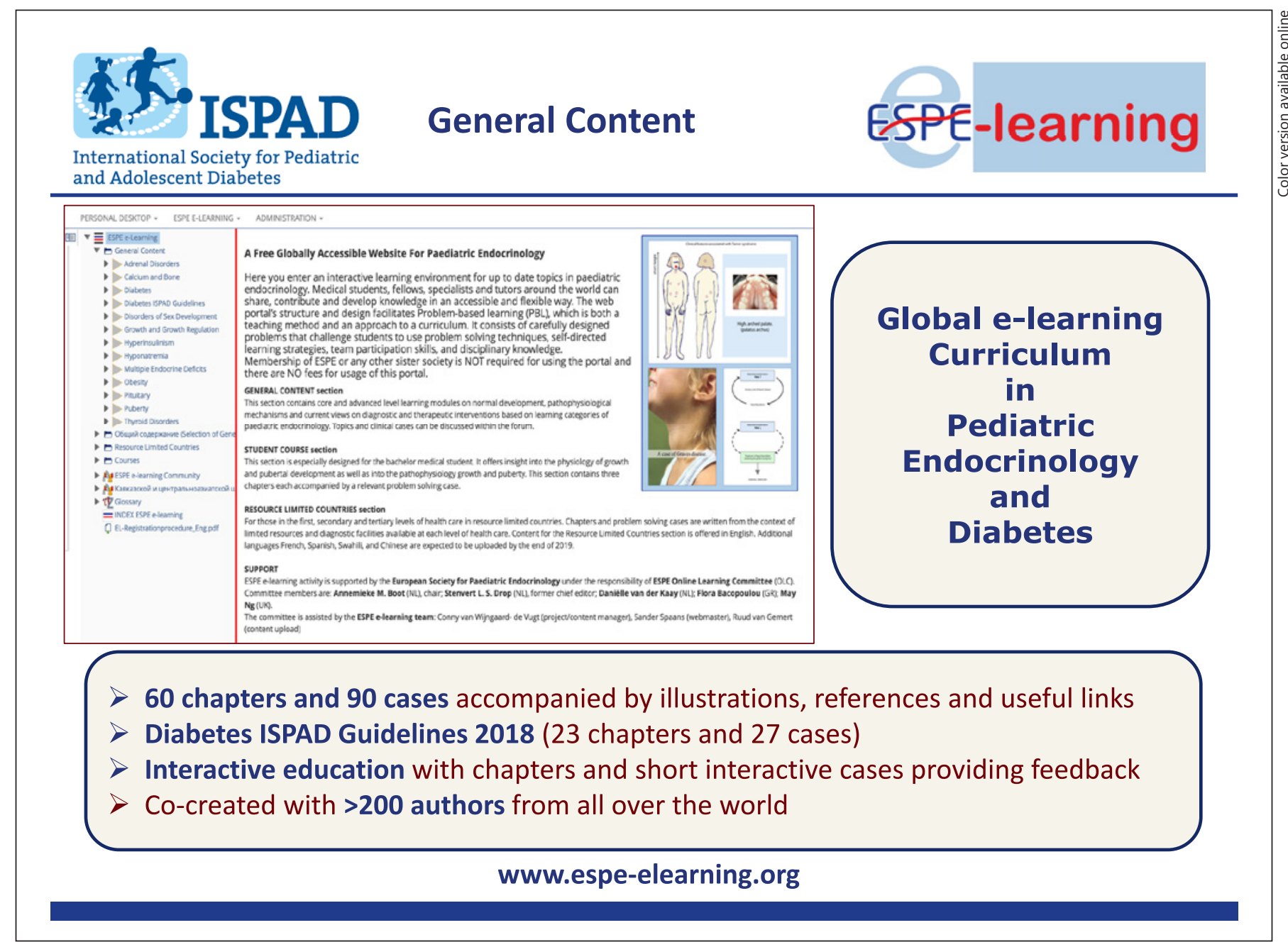

Fig. 1. ESPE-ISPAD introduction and description. ESPE-ISPAD, European Society for Pediatric EndocrinologyInternational Society for Pediatric and Adolescent Diabetes.

\section{E-Learning Platform}

The International Society for Pediatric and Adolescent Diabetes-European Society for Pediatric Endocrinology (ISPAD-ESPE) e-learning global web portal (www.espeelearning.org) was created in a collaboration between the ISPAD and the ESPE. This is an interactive e-learning environment for up-to-date topics in pediatric endocrinology and diabetes mellitus. The e-learning committee (ELC) for ESPE and ISPAD is jointly responsible for creating and maintaining the e-learning platform and for the development and quality of its content, which currently consists of 78 chapters and over 120 problem-solving clinical cases. Through this, freely accessible Internet e-learning portal, medical students, fellows, specialists, nurses, and tutors around the world can share, contribute, and develop their knowledge through the use of interactive chapters and case-based learning that covers core and advanced level learning modules. These include normal physical growth and development, pathophysiological mechanisms, and current views on diagnostic and therapeutic interventions for a wide variety of commonly encountered disorders in pediatric endocrinology and diabetes mellitus (Fig. 1). The entire content has been created and reviewed voluntarily by international experts in diabetes and endocrinology. The objective of the ISPAD-ESPE freely accessible e-learning resource is to improve the education and training of health-care professionals and, thereby, to improve the quality, safety, and health of children and adolescents with diabetes and endocrine conditions globally. 


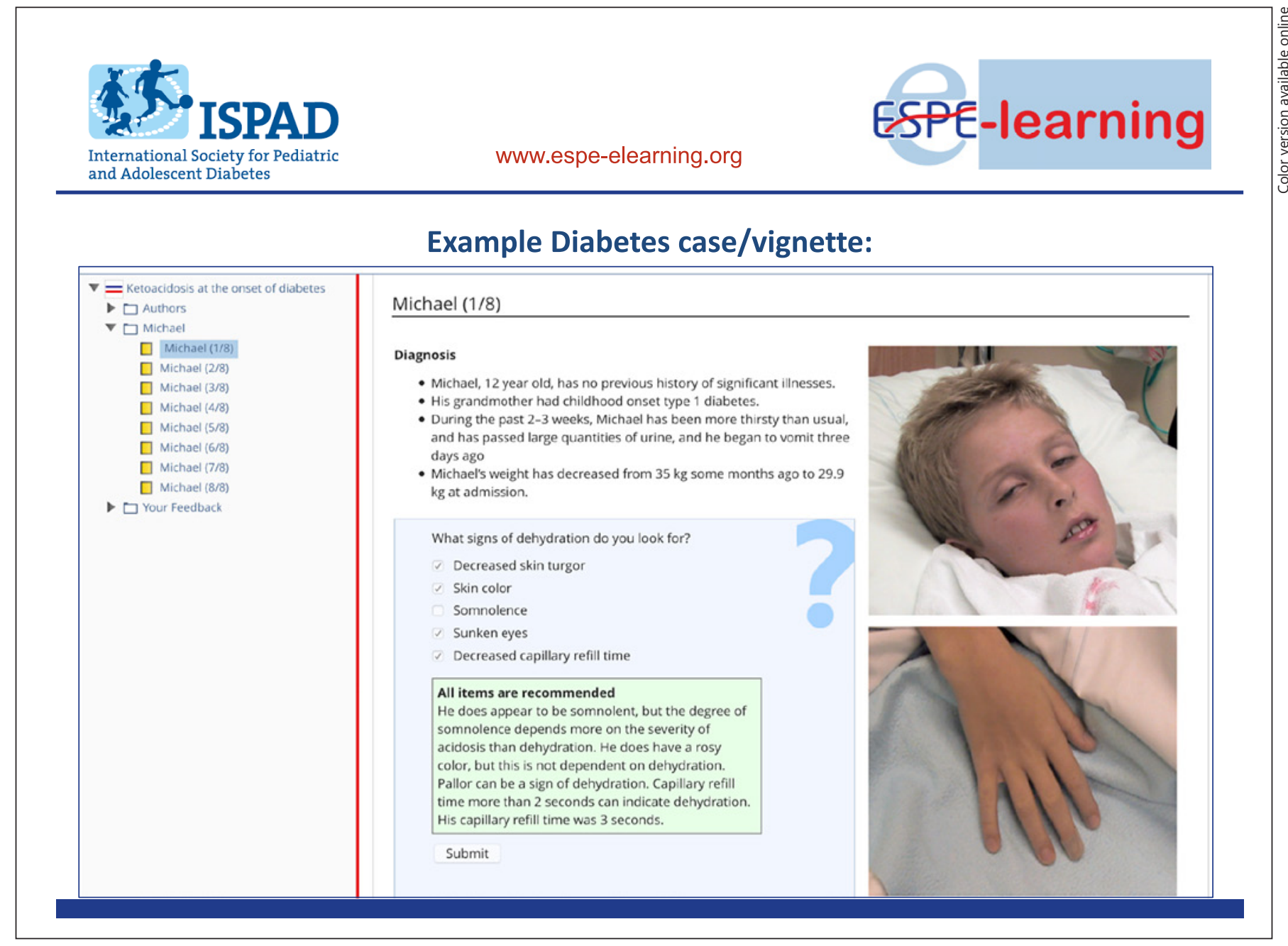

Fig. 2. Example of diabetes ketoacidosis case.

The ISPAD-ESPE e-learning global web portal provides a rich source of up-to-date information freely accessible through an automated login procedure and can be viewed on computers and mobile devices. Chapters and case-based discussions on a wide variety of pediatric endocrine and diabetes core subjects describe physiology and pathophysiology, along with practical approaches to management and treatment of both common and rare conditions. The chapters are presented in an easy-to-view bullet point format. Each chapter is accompanied by reallife clinical cases so that learners can apply their knowledge to diagnose and manage specific conditions in a stepwise and interactive manner (Fig. 2). The ESPE elearning for resource-limited countries (RLC) modules were further developed and specifically targeted for frontline health-care providers, medical doctors, and special- ists in RLC [7]. The RLC modules provide an up-to-date globally accessible multilingual curriculum in 4 other languages: French, Spanish, Swahili, and Chinese, enabling access to non-English speaking health-care professionals and students.

At the present time, approximately 15,000 individuals from 154 countries are using this free global e-learning platform, which benefits many countries and regions of the world with limited educational resources. With the exponential growth in health information, clinicians and students with limited time for continuing education require customized education that is tailored to their specific learning needs. E-learning platforms such as the ISPAD-ESPE e-learning global web portal can be more readily updated and customized to the participants' needs and is able to reach geographically dispersed health pro- 
fessionals. It also has the potential to cater to various training needs of health-care professionals at different stages of their careers. In the latter part of 2021, the Accreditation Council for Continuing Medical Education credits will be available for certain core modules within pediatric diabetes and endocrinology to provide continuing medical education for physicians.

Health-care professionals are encouraged to advocate and implement the use of the free ISPAD-ESPE e-learning portal within their practices and teaching programs. While the global e-learning platform has been successfully implemented, the objectives in establishing, maintaining, and frequently updating content within the elearning environment is a laborious, time-consuming, and complex task that requires a dedicated team of content experts willing voluntarily to provide their time. We continue to invite individuals who may be interested in becoming authors, reviewers, or who may wish to create new chapters or case studies within the modules for pediatric endocrinology and diabetes to contact info@espe-elearning.org.

E-learning will undoubtedly continue to be an important modality to deliver effective academic training and education during the disruption to education and training schedules from the COVID-19 pandemic. It can be the perfect platform for spread of consistent and reliable information, ensuring that learners are kept up to date with the latest developments. It can be used to deliver identical standards of training and education to professionals across the globe or be customized to meet the specific needs of its users. In the future and after the pandemic, we believe that hybrid learning strategies, which include in-person and e-learning platforms, will likely become the universal mode of delivering health education.

\section{Acknowledgements}

We thank the ESPE-ISPAD ELC members: Annemieke M. Boot (Netherlands), Chair; Flora Bacopoulou (Greece); Sze May $\mathrm{Ng}$ (UK); Abdulsalam AbuLibdeh (Israel); Zacharoula Karabouta (Greece); Evangelia Kalaitzoglou (USA), coordinator RLC section. Co-opted member Carine de Beaufort (Luxembourg) - formerly Secretary-General and currently President of ISPAD. We also thank Professor Dorothy Becker, former editor-in-chief of the ISPAD e-learning editorial board. The ESPE-ISPAD platform is assisted by the e-learning team Conny van Wijngaard-de Vugt (project manager) and Sander Spaans (webmaster). We gratefully thank all contributing authors who have volunteered many hours of their time toward the educational material. Special thanks to Professor Stenvert L.S. Drop, former chief editor of the ESPE elearning portal.

\section{Statement of Ethics}

Permission has been granted from the parents and patients to publish the photos and case description.

\section{Conflict of Interest Statement}

Sze May Ng is Chair of the UK Association of Children's Diabetes Clinicians and in the ELC for both ESPE and ISPAD. Carine de Beufort is the current President of ISPAD. Anniemieke Boot is chair of the ESPE ELC. Dorothy Becker is the former Editor-inChief of the ISPAD e-learning editorial board. Joseph I. Wolfsdorf is the current Chair of the ISPAD ELC and a Past President of ISPAD and is the Associate Editor of the journal.

\section{Funding Sources}

Espe-elearning.org online learning portal has received financial support from: The ESPE. The ISPAD. Kyowa Kirin, Japan. Sandoz International, Germany. Alexion Pharmaceuticals, USA. The European Union's Seventh Framework Program (FP7/20072013) under grant agreement No. 2014444. RLC Project has received financial support from: The ESPE. The ISPAD Eli Lilly \&Co., USA.

\section{Author Contributions}

S.M.N. and J.I.W. wrote the initial draft. All the authors approved the final draft.

\section{References}

1 Cook DA, Triola MM. What is the role of e-learning? Looking past the hype. Med Educ. 2014;48(9):930-7.

2 Cook DA, Levinson AJ, Garside S, Dupras DM, Erwin PJ, Montori VM. Internet-based learning in the health professions: a meta-analysis. JAMA. 2008;300(10):1181-96.

3 Cook DA, Levinson AJ, Garside S. Time and learning efficiency in internet-based learning: a systematic review and meta-analysis. Adv Health Sci Educ Theory Pract. 2010;15(5):755-70.

4 Maloney S, Nicklen P, Rivers G, Foo J, Ooi YY, Reeves S, et al. A costeffectiveness analysis of blended versus face-to-face delivery of evidencebased medicine to medical students. J Med Internet Res. 2015;17(7):e182.

5 Glass NE, Kulaylat AN, Zheng F, Glarner CE, Economopoulos KP, Hamed $\mathrm{OH}$, et al. A national survey of educational resources utilized by the resident and associate society of the American College of surgeons membership. Am J Surg. 2015;209(1):59-64.

6 Arkorful V, Abaidoo N. The role of e-learning, the advantages and disadvantages of its adoption in Higher Education. Int J Educ Res. 2014; 2(12): 14 .

7 Kalaitzoglou E, Majaliwa E, Zacharin M, de Beaufort C, Chanoine JP, van Wijngaard-DeVugt C, et al. Multilingual global E-learning pediatric endocrinology and diabetes curriculum for front line health care providers in resource-limited countries: development study. JMIR Form Res. 2020; 4(11):e18555. 